\title{
Chapter 36 \\ Origins and Evolution of Religion \\ from a Darwinian Point of View: \\ Synthesis of Different Theories
}

\author{
Pierrick Bourrat
}

\begin{abstract}
The religious phenomenon is a complex one in many respects. In recent years an increasing number of theories on the origin and evolution of religion have been put forward. Each one of these theories rests on a Darwinian framework but there is a lot of disagreement about which bits of the framework account best for the evolution of religion. Is religion primarily a by-product of some adaptation? Is it itself an adaptation, and if it is, does it beneficiate individuals or groups? In this chapter, I review a number of theories that link religion to cooperation and show that these theories, contrary to what is often suggested in the literature, are not mutually exclusive. As I present each theory, I delineate an integrative framework that allows distinguishing the explanandum of each theory. Once this is done, it becomes clear that some theories provide good explanations for the origin of religion but not so good explanations for its maintenance and vice versa. Similarly some explanations are good explanations for the evolution of religious individual level traits but not so good explanations for traits hard to define at the individual level. I suggest that to fully understand the religious phenomenon, integrating in a systematic way the different theories and the data is a more successful approach.
\end{abstract}

\section{Introduction}

Over the last 15 years, the religious phenomenon has sparked an increasing interest among evolutionists. Although there is only one Darwinian Theory of evolution, there is a myriad of theories proposing an evolutionary and Darwinian explanation of the origin and evolution of religious beliefs and practices. An obvious reason to this is that religion is an extremely complex phenomenon which can be carved not only in different cultural traits that can themselves be studied independently, but also from different points of view. Indeed, one can study rituals, beliefs in supernatural entities or the economical aspects of religions which all belong to the

\footnotetext{
P. Bourrat $(\square)$

Department of Philosophy, University of Sydney, Sydney, Australia

e-mail: p.bourrat@gmail.com; https://sites.google.com/site/pbourrat/
} 
phenomenon of religion. Matching with these different aspects of religion, some theories focus more on the cognitive aspect of religion while others see the phenomenon from a larger perspective. Yet, the complexity of the phenomenon is not the only reason for the numerous Darwinian theories of religion. Another reason is sociological. Although all of these theories claim to be Darwinian, they have been developed in different fields. Some come from evolutionary biology, others from psychology, cognitive sciences, anthropology or economics. Those fields comprehend Darwinism in different ways. For example, a postulate of evolutionary psychology is that many of the human psychological adaptations have been shaped in an ancestral environment which was very different from our modern setting. This would have led some of our behaviors to be mismatched with the modern environment. However, this is not a postulate of human behavioral ecology or evolutionary anthropology. Indeed, in these fields it is postulated that our modern behaviors are optimal from an adaptive point of view (relatively to some tradeoffs an organism cannot avoid). These different ways of conceptualizing evolutionary mechanisms and Darwinism have subsequently led to different paradigms when religion has started to be a hot topic in evolutionary sciences.

Aside from their number, another remarkable fact of the Darwinian theories of religion is that they are often presented as incompatible or mutually exclusive. For example, according to different theories, the beliefs in supernatural agents are either a byproduct of our social evolution or an adaptation. And among the adaptive theories, these beliefs are either individual adaptations with the function of maintaining one's reputation or group adaptations with the function of reinforcing social cohesion. This kind of divergence is, I have already noted, partially explained by the different origins of the Darwinian theories of religion. Yet, in many cases, I will show that these oppositions are fallacious. In fact, it is possible to integrate the different theories if one pays attention to what explanatory level, level of organization and temporal scale they operate at. At the end of the chapter, I will argue that each of these oppositions is often the result of a lack of precision in the phenomena explained the theories. While being rarely expressed, some theories explain the origin of some religious phenomena while other theories explain some religious phenomena in an actual context. Similarly, the different theories study one and the same phenomenon using different scales, whether spatial or temporal. More generally, this chapter will be an integrative synthesis of the different Darwinian theories of religion. The integration I will propose will have the beneficial effect to palliate different problems encountered by each separate theory while still keeping their explanatory power. Although some research has been conducted in order to treat several levels of organization at once with religion (see for example Johnson and Bering 2009; Roes and Raymond 2003; Sosis and Alcorta 2003; Sosis et al. 2007), more work needs to be done in order to understand the articulation of these different levels. My aim in this chapter will be an attempt to make this articulation. For each theory I present, I will ask the following questions "Does this theory give an explanation of a phenomenon encountered in religions or does it provide an explanation of the stabilization of this phenomenon?" or "Can this 
theory be treated independently from any other or does it relate to (even implicitly) parts of other theories?"

This synthesis, however, will not be exhaustive. There are at least two reasons for that. First, disagreements within each discipline exist and presenting them would exceed the scope of this chapter. Second, among the different perspectives one can adopt on religion, my synthesis will mostly focus on cooperation. Indeed, many theories propose that one of the evolutionary functions of religion is to increase cooperation between individuals. The problem of cooperation is one of the most important in evolutionary sciences and focusing on religion from this point of view is up to now the most fertile research program involving Darwinian Theory. However, it would be inaccurate to claim it is the only one.

The theories I will examine will be classified in three categories. The first category is the by-product theory of religion (Barrett 2000; Boyer 2001; Boyer and Ramble 2001) which is undeniably the most popular and also the strongest from an empirical point of view. According to this theory, the religious phenomenon, or more precisely the beliefs in supernatural agents, is not an adaptation. Rather, its proponents believe it is a by-product of other adaptations to sociality. Another corpus of theories, on the contrary, seeks to explain the religious phenomena as past or actual adaptations. These theories are the theories stemming from Evolutionary Psychology (Dennett 2006), the fear of supernatural punishment theory (Johnson and Bering 2009), the costly signaling theory of religion (Alcorta and Sosis 2005; Cronk 1994; Sosis and Alcorta 2003; Sosis et al. 2007) and the kleptocracy theory (Diamond 1997). Finally, a third type of theories sees religion from a multilevel and adaptive point of view. In particular, they consider the group level as a privileged level upon which selection is acting (Roes and Raymond 2003; Snarey 1996; Wilson 2002, 2005). Following the three types of theories I have just pointed out, the remainder of this chapter will be divided into three sections. The first section will focus on the by-product theory of religion, while sections two and three will focus on adaptive theories of religion that regard the individual and the group as the privileged level of selection respectively. In sections two and three, the theories I will present are solutions to the problem of cooperation. I will show that schematically there are two potential solutions involving religion with the problem of cooperation. These solutions match with the theories focusing on the individual and those focusing on the group. The first solution proposes that an individual cooperate because their reputation is involved. If they do not cooperate, their reputation and consequently their fitness might suffer from it. The second solution focuses on the idea that selection operates at the level of the group. Individuals cooperate because it increases group fitness, sometimes at the expense of their own fitness. If they do not, their group might get extinct or be outcompeted by another one. The division between these two forms of adaptive theories will be very schematic. Indeed, soon I will show that in some theories the level upon which selection acts will be difficult to delimitate; it will be possible to conceive that individuals cooperate both for themselves and their group. 


\section{The By-product Theory of Religion}

I will first present the by-product theory of religion, which was originally developed within the field of cognitive sciences. It proposes that the beliefs in supernatural agents are principally the consequence of selective pressure cognitive traits which are (or were) critical for the survival of individuals in their environment, rather than an adaptation. Buss et al. (1998, p. 537) define by-products as "[...] characteristics that do not solve adaptive problems and do not have to have functional design. They are carried along with characteristics that do have functional design because they happen to be coupled with those adaptations." In the present, case with belief in supernatural agents, two traits or characteristics have been distinguished.

\subsection{Two Critical Traits}

The first of these two traits is what Justin Barrett (2000) calls Hypersensitive Agency Detection Device (HADD). This expression comes from an argument developed by Stewart Guthrie who proposes that humans are naturally predisposed to detect agents in their environment when such agents do not actually exist (Barrett 2000; Guthrie 1993; Tremlin 2006). One classical example given by Stewart Guthrie (1993) is the clouds one can sometimes see shaped as faces, a phenomenon which gave the title to his book. According to Guthrie, such a perceptual device (although biased) could have been adaptive in our evolutionary past. Indeed, in an uncertain environment failing to detect an agent could have had much more dramatic consequences for survival than detecting an agent where there was none. Let us imagine, for example, that this agent is an enemy or a predator: failing to notice its presence in time could be fatal. An analogy between this type of cognitive bias and a fire alarm can be made. If a fire alarm is very sensitive and goes off very often, even when there is no fire, it will always be a better alarm than an alarm which does not go off when there is a fire. Because of this asymmetry, one should expect a fire alarm to be designed in a way that it goes off more often than there are fires. Following the same reasoning but applying it to an evolutionary context, one should expect that humans (and other organisms) detect agents in their environment more often than there actually are. Beliefs in supernatural agents would be the result of a manifestation of this cognitive bias.

The second trait, which together with HADD makes belief in supernatural agents possible, is the theory of mind module. Theory of mind is defined as the ability for one individual to impute mental states to others (Premack and Woodruff 1978). For obvious reasons, this ability is crucial for humans. Although there is no or little research made on this topic, it seems that people who do not have it or possess it in a very limited way, such as autistic people (Baron-Cohen 1995; Bloom 2004; Pinker 1997), develop beliefs in God which are very different from the majority of us. These beliefs do not imply the existence of God as a supernatural agent but more as 
a force or general principle (Atran 2002; Bering 2002; Tremlin 2006). The key point with the theory of mind and its relation to supernatural agents is that it suggests that humans are predisposed to conceptualize anthropomorphically the supernatural agents in which they believe, in other words, with human traits and preoccupations. For example, Barrett and Keil (1996) have shown that when students who claim not to have an anthropomorphic understanding of God, were asked to answer very quickly to questions about its supernatural powers, they were shaping their answer anthropomorphically. In fact, although the participants of this experiment had a conception of God as omnipotent (i.e. non-anthropomorphic) in their religion, when they had to answer quickly and intuitively to some questions about God, their answers showed that they were not conceptualizing it as omnipotent as they were claiming. Rather they thought of God as being able to execute only one action at a time (i.e. anthropomorphic).

Boyer (2001), from a rather anthropological background, and Barrett (2004), from an experimental psychological background, both propose a detailed account of the by-product theory of religion.

\subsection{Religion Is Too Complex to Be Only a By-product}

Although very young, the Cognitive Science of Religion from which the by-product theory of religion emerged, could become extremely fertile in the near future because it proposes new approaches to study religion. Yet, one can detect a limit to this approach and more specifically to the by-product theory: whereas it can provide an explanation of the emergence or the origins of some religious behaviors and beliefs, its explanatory power plummets when one tries to explain why supernatural agents, religions and rituals can sometimes be so elaborated. Let's recall the definition of a by-product from Buss et al. (1998) given earlier. If one follows this definition and subscribes to the by-product theory, beliefs in supernatural agents are only a by-product of HADD and of the Theory of Mind module. However, it is legitimate to question why, on top of their anthropomorphic characteristics, those agents have other characteristics such as being all-powerful, benevolent or having created the universe etc. The proposition that religion is only a by-product of the architecture of our mind (directly inherited from our evolutionary past) implicitly commits us to deny that from the emergence of those by-products, natural selection did act upon them. Yet, it seems a priori reasonable to think that some processes of natural selection whether biological or cultural did happen since then. Some characteristics of supernatural agents are observed with regularity and transculturally, and they do not seem to have no direct links either with the HADD or with the Theory of Mind module. It is moreover difficult to conceive how these characteristics could only be cognitive by-products. The theories that I will examine in sections two and three propose precisely that the different patterns one can observe are adaptations or at least have an adaptive role in human societies. Thus, by-product theory - although an important hypothesis for the origin of religion and a starting point for other 
evolutionary theories of religion - does not allow for a complete explanation of the beliefs in supernatural agents, let alone the religious phenomenon in its totality.

\section{Adaptive Theories at the Individual Level}

\subsection{Religion as an Ancestral Adaptation Which Is Not Anymore: "Sweet-Tooth" Theories of Religion}

"Sweet-tooth theories of religion" is a label given by Daniel Dennett (2006) to a body of evolutionary theories on religious beliefs and practices. The main idea behind this label is that religion has incorporated some characteristics which were adaptive in our evolutionary past, but nowadays they are not anymore. Dennett compares religions to the sweet and fatty foods most of us like, which were probably rare for our ancestors. There is little doubt that such food was providing a selective advantage to the individuals who had access to it. Yet, in our modern environment, this kind of food is not rare anymore and have deleterious effects (such as hypercholesterolemia, diabetes etc.) if consumed in excessive quantities. In spite of this mismatch, it is still attractive for us. Mismatch theory is a classical concept of evolutionary psychology. A mismatch occurs when an individual is not adapted to its environment any more. The cause of the mismatch is that the environment has evolved too quickly for new adaptive solutions to be found. We can use the idea that we are not adapted to our modern environment rich in sweet and fatty food, in regards to religion. In fact, it is possible to conceive religious beliefs and practices as costly or neutral (from an evolutionary point of view) nowadays, when they incite individuals to cooperate more. An individual may incur net costs by cooperating in an anonymous society where no one else cooperates. However, cooperating through the means of religion may have been evolutionarily advantageous when conditions where different. Advantages may have been, for example, to allow for a better cooperation within small groups of individuals, so that beliefs and practices which made cooperation easier would have been selected. Subsequently, according to sweet tooth theories, because the environmental conditions have suddenly changed, the beliefs and religious practices lost their adaptedness (that is, their function in social cohesion) but remained attractive for the human mind. Thus, under this view, Christianity, Judaism or Islam could be seen as cultural phenomena which have been invented and selected by humans because they reunite a combination of attractive ideas, yet they would have no evolutionary function nowadays. To push our analogy between food and religion a little further, our sweet tooth and taste for fatty food pushed humans to create and eat fast food which has a lot of success all around the world in spite of its deleterious effects. Similarly, our spiritual intuitions which were adaptive in the past might have had a great influence on our modern religions and would simply be a very good synthesis of the different traits which were one day adaptive. 
This idea fits perfectly with the framework of Evolutionary Psychology and would deserve further developments more. Yet, Dennett does not point out any precise study confirming his ideas. Indeed, he remains rather vague on the potential function religion might have had. Although it might be difficult to test hypothesis about the past, it is worth verifying the compatibility of those hypotheses with the different evolutionary scenarios of human evolution. But even if research could be done, it would have to show that religion does not have any influence on fitness nowadays. The same demonstration would also need to be done with the by-product theory of religion. But in the latter case it would be less problematic since the byproduct theory makes almost no assumptions on the ancestral environment in which beliefs in supernatural agents did appear except that it was a social one. Finally, although it seems quite probable and reasonable to think that some religious traits have been adaptive in our evolutionary past, it seems equally reasonable to think, as I already mentioned in the previous section, that the same or new religious traits are adaptive today. Indeed, some authors consider the by-product and sweet-tooth theories as insufficient to fully explain the religious phenomena, and argue that some religious traits do have an adaptive role nowadays.

\subsection{Religion as a Contemporary Adaptive Phenomenon at the Individual Level}

\subsubsection{The Fear of Supernatural Punishment Theory}

The fear of supernatural punishment theory, mainly defended by Jesse Bering and Dominic Johnson (Johnson 2005; Johnson and Bering 2009), also has its roots in cognitive sciences. The Theory of Mind and HADD have, according to this theory, strictly the same role that in the by-product theory. However, this theory takes into account a new constraint on evolutionary dynamic which is different from all the constraints the by-product theory assumes, namely language. This constraint is the most important pillar of the fear of supernatural punishment theory. Bering and Johnson propose that together with the birth of human language and Theory of Mind, reputation becomes an essential characteristic of humans. According to them, language permits a rapid dispersal of ideas and information of the type "who did what". The emergence of human-like language would hence impose nolens volens new selective pressures on individuals through the reputation they acquire. A bad reputation is extremely disadvantageous and cooperation might be a strategy which would mitigate this problem by preventing an individual from acquiring such a reputation. Although it can be costly to cooperate, the net balance between the costs and benefits of cooperation is often positive in contexts where reputation is important.

Starting from these hypotheses, Johnson and Bering propose that beliefs in supernatural agents are means to avoid the consequences of a bad reputation by increasing individual's cooperation. Let us recall that HADD and the Theory of 
Mind module are responsible for the concepts of anthropomorphic supernatural agents. The HADD erroneously recognizes agents in the environment and the Theory of Mind gives these agents human-like intentions. Let us now posulate that an individual believes that an ancestor, or any other supernatural agent they believe in, will punish them if they act antisocially within their community. Johnson and Bering consider that, on average, such an individual will acquire a better reputation relatively to another individual who does not have these beliefs since the former, because of their fear in supernatural punishment, will have an incentive to have less antisocial behaviors. This will lead our individual to have a fitness-classically defined as the product of the survival and reproduction-ceteris paribus superior to an individual who does not have such beliefs. If those beliefs are heritable, they will be transmitted to the next generations and selected by natural selection because of the selective advantage they procure: if an individual believes they are constantly observed by someone, as it could be the case if they believe in the existence of a god who can punish them, their incentive (whether conscious or unconscious) to be prosocial ${ }^{1}$ will be strong since they will feel monitored by this god. However, such constraint is not imposed on individuals who do not have beliefs in supernatural agents, and although they might overall be prosocial, they will be more likely to be caught while committing acts of selfish behavior which will damage their reputation and, as a result, reduce their fitness.

The fear of supernatural punishment theory seems at first glance promising and contrary to sweet-tooth theory easily testable. As a matter of fact, Johnson and Bering claim that this theory has an empirical support (Bering et al. 2005; Johnson 2005). Yet, it has many limits and its testability is an extremely delicate matter. Enumerating these limits here would be beyond the scope of this article, and for that reason I will restrain my analysis to the most important of them (for more details on these limits see: Bourrat et al. 2011). One of the most important limits of Johnson and Bering's ideas is that they are presented as a theory in which the only important level of selection is the individual level. Yet, reputation is only a strong constraint for a given individual with the members of the group she interacts with. In fact, it intuitively seems much more problematic when your neighbor has a bad opinion about you rather than someone you do not know and who lives 3,000 km away. Once this remark is taken into account seriously, it becomes clear that the fear of supernatural punishment theory can be of great help for understanding beliefs in moralizing supernatural agents from a Darwinian point of view, but only in the context of unique or isolated groups. Nowadays, the context is different, numerous groups of individuals with different beliefs exist and virtually none of them is isolated. The fear of supernatural punishment theory as proposed by Bering and Johnson is insufficient to give an account of all the characteristics linked to cooperation and the beliefs of the different supernatural agents one can observe in different groups. This theory can hardly explain why different human groups have beliefs in different supernatural agents and punishments or why the supernatural punishments believed in one group are not believed as threatening in other groups. At best, the fear of

${ }^{1}$ By "prosocial" here I mean "having a propensity to cooperate with others". 
supernatural punishment theory is part of a larger explanation of the evolution of beliefs in supernatural agents. That said, it is more refined when compared to the by-product theory because it provides a partial explanation of why humans often believe in supernatural agents who have moral virtues and are inclined to punish.

Another limit to this theory comes from its mitigated empirical results. Johnson (2005) has tested it transculturally using a database of 186 societies and with more than 2,000 variables. Some of them were linked to religious and supernatural beliefs while other being were to cooperation. As he claims, the results reinforce the hypothesis of fear of supernatural punishment as a mechanism explaining (at least partially) the different levels of cooperation, whether it occurs directly between individuals (e.g., not robbing your neighbor) or are institutionalized (e.g., the existence of a currency or a police as part of the society). Bourrat et al. (2011) have tested this hypothesis again using the same database, but they started with the premise that the fear of supernatural punishment hypothesis should be valid not only for supernatural agents which are not gods or ancestors (while Johnson was only considering high gods) but also for any other forms of supernatural punishment, as Johnson and Krüger (2004) initially proposed it. Indeed, no criteria in the theory can justify a special treatment for religious supernatural agents. Bourrat and colleagues also underlined that the theory can only account for the direct cooperation between individuals and not for institutional cooperation. The results they obtained could not confirm the fear of supernatural punishment hypothesis. That said, they consider that the anthropological database they used is not fine-grained and precise enough to detect personal beliefs. Atkinson and Bourrat (2011) have therefore tested this hypothesis yet again, using a database reporting personal beliefs. Their result seems to support the fear of supernatural punishment hypothesis in its broader version, that is, which is not limited only to supernatural agents.

\subsubsection{The Costly Signaling Theory Applied to Religion}

The costly signaling theory applied to religion focuses on another specific aspect of the religious phenomenon, namely rituals. However, this theory has been developed from the perspective of cooperation, similarly to the theories I have discussed earlier.

The costly signaling theory has been developed mostly by evolutionary biologists and has its roots in the work of John Krebs and Richard Dawkins (Dawkins and Krebs 1978; Krebs and Dawkins 1984) on manipulation of signals, and of Amotz Zahavi (1975) on the handicap principle. Krebs and Dawkins propose that signals should be seen as attempts to manipulate individuals rather than attempts to inform them. This idea is one of the pillars of Dawkins' concept of extended phenotype (Dawkins 1982), in which the phenotype of an individual is not only the direct expression of their genes, but also the way this individual modifies their environment including others' behaviors. In a revised version of the manipulation of signals theory, Krebs and Dawkins (1984) defend the idea that the use of signals should be regarded as manipulative or cooperative attempts depending on signaler and receiver 
individuals' interests. When signalers and receivers do not have overlapping interests, receivers should undergo strong selection pressure to detect and resist the attempt of manipulation from the signaler. In return, this should create a selective pressure on signalers to develop new strategies of manipulating the receivers and so forth ad infinitum. This phenomenon is typical of arm races such as described by the Red Queen Hypothesis (Van Valen 1973). Krebs and Dawkins argue that when signalers and receivers have overlapping interests, the signal is expected to be simpler: manipulation is not in the evolutionary interests of the signaler since it is also in the interests of the receiver to cooperate.

The handicap principle proposes, among other things, that males, in a context of sexual selection, should display their qualities to females by inflicting a cost to themselves (Zahavi 1975; hence the name of the principle). For example the long peacock tail displayed by males is very costly to have. Nevertheless, because a long and colorful tail increases the chances for an individual to be predated and is costly to produce and maintain, a peacock male with such a tail signals to females that in spite of this handicap it has been able to survive. A female choosing to mate with this male consequently selects his qualities.

In the framework of Krebs and Dawkins, the handicap principle matches with a case of cooperation between signalers and receivers (hence no arm race between them is expected), but in a context of possible defection. Indeed, Krebs and Dawkins draw their attention to many cases of signals where imitation is impossible, because there is an indispensable link between the signal and the underlying necessary condition for it to exist. This is the case, for example, between body size and frequency of vocal signals. In this case, no arm race between signalers is expected since no "cheap" imitation will be convincing. Yet, as suggested by Zahavi (1975), even when such a link between the signal and the underlying condition for this signal does not exist naturally, signals which are costly to produce would be honest signals for the receivers and would allow them to distinguish good quality signals from bad quality ones. In those conditions, a signal will be honest if and only if the cost of imitation is as or more important than the benefits that would be received from that imitation (Grafen 1990) and an arm race between signalers is expected until a point where only some individuals can pay the costs. This idea precisely fits the case of the peacock tail. There is no direct trait naturally measuring the propensity of a male to avoid predators. Yet, the cost of producing a long tail becomes a reliable signal for females who will choose the males with the longest tails.

Several scholars have proposed to apply these ideas to human rituals (Cronk 1994; Irons 1996; Sosis and Alcorta 2003). They suggest that the function of rituals is to promote cooperation within a group, community or society which will only be possible if the rituals are costly to exercise. For example, we can find frightening or painful rites of passage ceremonies, including tattooing and scarification in numerous societies. These rituals, as well as many others, can be interpreted as signals displaying a commitment to the community or wider society. Individuals undergoing them show that they truly want to be part of the community 
since they are willing to pay a price for it. By doing so they demonstrate that in future they will not free ride when it will be possible since the cost of free riding would be superior to the cost undergone during the ceremony or ritual. For instance, Sosis et al. (2007) have proposed that the tattoos, genital mutilations and scarification that some men undergo during different rituals signal the belonging to a group. When a man accepts to be marked by tattoos, scarification and mutilations, it will be impossible for him to move from the group to another one in future. Indeed with the permanent mark of the group he belonged initially it would be very hard for him to be accepted in another group in full trust. Hence, these definitive marks represent reliable signals of future cooperation since being banned from a group would be extremely costly. However, a signal can be costly in different ways: the same absolute cost can be undergone in one shot, as it is the case with initiations, or undergone over time, as it is the case with rituals such as catholic masses (cost in terms of time spent). These two "types" of costs perfectly correlate with the two forms of religiosity one can find transculturally: "doctrinal" and "imagistic"(Atkinson and Whitehouse 2011; Whitehouse 2004). In a doctrinal mode, religiosity is acquired through the practices of frequent but low arousal rituals such as masses. In the imagistic mode, religiosity is acquired through the practices of highly arousing but very infrequent rituals, such as initiations which individuals remember all their life.

The costly signaling theory applied to rituals has a promising explanatory power and there is already interesting research suggesting its value. This is the case with the work of Richard Sosis and his colleagues (Sosis et al. 2007) on scarifications and on American communities in the nineteenth century (Sosis 2000; Sosis and Bressler 2003). Furthermore, the costly signaling theory can be applied to a vast range of human behaviors and in different contexts. In the field of religion, for example, Terence Deacon (1997) proposes that the commitment of women to religion such as Christianity or Judaism, in some societies, could be an honest signal of their fidelity. The rationale behind this idea is that pious women should be, in principle, more reluctant to be unfaithful than other women. The fear of supernatural punishment could be, in this case, the underlying mechanism of some honest religious signals. As there is no direct observable expression of fidelity, piety can be one proxy for it. Hence, demonstrations of piety are expected to be stronger and more explicit when the fidelity of women is under selection pressure. This prediction is supported by the research of Boster et al. (1998) on certainty of paternity which is superior with Jewish priests. The authors argue that the laws of sexual purity to whish Jewish women are committed is the reason of this result. Such commitment can be translated in terms of costly signals as Sosis and Alcorta (2003) do. That said, this theory which comes directly from behavioral ecology and mostly focuses on the biological individual has some limits. For example, it is hard to conceive why some cultural traits increasing the fitness of individuals on the long term (such as rituals) would be so widespread in human societies without invoking a form of cultural group selection. I will come back to this problem in the fourth section. 


\subsubsection{The Kleptocracy Theory of Religion}

The kleptocracy theory, although being very general, is not a theory of religious beliefs and practices that one can apply to any society, unlike the theories we examined thus far. Rather, it focuses on the evolution of religion in agrarian societies, the only ones in which an important social stratification is possible. The concept of kleptocracy has its roots in the Marxist argument proposing that religion is created by the societies' elites in order to materially exploit the people who only receive the secondary or derived benefits of a low but constant level of security and productivity (Atran 2002).

According to Jared Diamond (Diamond 1997), the "true" religions only emerge when a central authority assimilates the beliefs in the supernatural in order to establish a pyramidal scam. Supernatural agents, in this case, can be conceived as a mean of reinforcing the power of kleptocrates (the ruling elite). The vast majority of individuals is exploited by them, but this system of exploitation is cooperative. Kleptocrates maintain the social cohesion of the group by force directly, but also and more importantly most the people truly believe that the ruling elite have a direct link with their $\operatorname{god}(\mathrm{s})$. Thus, this justifies their privileged position. It is almost certain that in past or present societies, the elite are healthier than other individuals (see Diamond 1987), especially in agrarian systems where food storing is the rule. Another demonstration of elite's privileged position is Laura Betzig's research (1986), which demonstrated transculturally with the help of anthropological data that the level of despotism is positively correlated to the size of harems in a society. Hence, we can imply that the fitness of the elite is usually superior to the fitness of the people in those societies.

Let us note that kleptocracy theory is compatible with the fear of supernatural punishment theory. This will be the case if one given individual believes that they will be punished by a god if they do not obey their monarch or sovereign. However, the fear of supernatural punishment is only one of the possible mechanisms that can reinforce obedience and submission, since cooperation between individuals might as well be the result of threats and direct punishments from the elite. Likewise, the enforcement of rituals might increase cooperation between individuals, as it has been recently argued: the synchronization of movements one can observe during rituals would have such an effect on people (Wiltermuth and Heath 2009). These two examples, which show how the elite can exploit the people for them to cooperate using religion as a justification, are however far from being exhaustive.

Although kleptocracy theory is very general and potentially embeds some theories I already examined, one question remains unanswered. If a kleptocracy decreases the fitness of most individuals but the elite, why were there so many kleptocracies in human history and why have they been so successful? One possible answer I propose is that the fitness of an individual in a kleptocratic society, in spite of being lower when compared to the fitness of an individual in a non-kleptocratic society, will become higher when the two societies will be in competition with each other. Indeed, a centralized power such as the one we can encounter in kleptocratic societies allows for the cooperation of a higher number of individuals which are 
more specialized (e.g. army, farmers etc.) than in a non kleptocratic society. These two parameters are critical when there is an intergroup competition (Alexander 1987). I will come back later to this point in the next section.

One of the strengths of kelptocracy theory is that it can allow the integration of many other theories from different fields, whether cognitive sciences, ecology or evolutionary sciences, but it is also one of its weaknesses since it makes it extremely hard to test precisely and in its totality. Another important point to note is that although this theory can give an account of the origin of "true religions" as defined by Diamond, the theory cannot explain why a kleptocratic society will be successful over time if one does not consider at least two levels of selection: the individual level and the group level. Diamond himself accounts for such possibility and proposes that a form of group selection could explain the success of kleptocratic societies (Diamond 1997).

\section{Adaptive Theories at the Group Level}

Individual level selection explanations have been privileged by evolutionary biology for more than 30 years (Wilson and Wilson 2007). However, many authors agree that major transitions took place in evolution. A major transition in evolution can be defined as the emergence of a new property that has dramatic consequences on the course of evolution. One family of major transitions is evolutionary transitions in individuality. An evolutionary transition in individuality is the result of the emergence of a new kind of individual from the cooperation of lower-level individuals (Maynard Smith and Szathmáry 1995; Michod 1999; Okasha 2006). The emergence of human language and culture is sometimes considered as the most recent evolutionary transition in individuality since it seems possible that the human cooperation leads to the formation of news "cultural" individuals in competition at the level of societies, namely human "superorganisms".

Until now, all the theories I have examined propose an explanation of the religious phenomena at the individual level, which implicitly or explicitly rests upon the concept of gene. Yet, we have seen the limits of these theories to explain the diversity of religions, whether it is diversity in supernatural agents, in rituals or supernatural punishments, which can be very different from one society to the other. To fill the gap between these gene-centered theories and the diversity of religious phenomena, it seems necessary to postulate some mechanisms of cultural evolution and selection in order to get more complete picture of the evolution of religion. This is exactly what David Sloan-Wilson (Wilson 2002, 2005) proposes. According to him, the evolutionary function of religion is essentially to favor the production of common goods within group and to diminish their costs through the altruistic cooperation of individuals belonging to one and the same group. This leads to the emergence of an intergroup competition when more than one group can be considered (direct competition if the groups are in contact and indirect if they are not). According to Wilson, it is hence perfectly legitimate to consider whether actual forms of religion are cultural adaptation at the group level. 
Wilson confirms his hypotheses using detailed case studies (Wilson 2002) and an analysis of 35 religions (Wilson 2005) randomly chosen in an encyclopedia of Religion. Although he recognizes the value and plausibility of the other Darwinian hypotheses we examined so far, he dismisses them one by one showing that none of them is able to provide a full explanation of the phenomena linked to the religious practices and beliefs. He propels his ideas with the introduction of the notions of cultural group selection and gene-culture coevolution (Richerson and Boyd 2005). In order to understand the interaction between genes and cultural items one has to notice that ultimately they have a common fate since they depend (in a different way) on the same interactor, namely the human biological individual. However, genes and cultural items (sometimes called memes) are fundamentally different on one point. Genes are prisoners of their interactors (or their "vehicles", to use Dawkins' terminology) except during an event of reproduction. Yet, that is not the case for cultural entities which can easily pass from one individual to the other during an act of communication. From this standpoint, we can understand culture from an epidemiological point of view. Indeed, models of cultural evolution based on the idea of contagion can be derived from models of virulence (Laland et al. 2000), since the cultural entities face the same constraints as biological parasites. For example, the practice of a transmissible religious altruistic behavior will successfully spread within a group if the cost of this practice (in terms of its fitness) is compensated by the number of "infected" individuals of this practice. Now, the number of individuals infected by the practice will depend on the number of individuals available in the population. In an ideal (thus unrealistic) case of population with infinite size and infinite density, biological and cultural evolutions could be strictly decoupled from each other. It would not matter in this case that the practice leads to the death of the "infected" individual if the number of available individuals is infinite and some of them adopt the practice. In this case, culture would impose no constraints on individual fitness. Yet, real populations are neither infinite nor infinitely dense. Consequently one given individual has a limited access to other individuals. Under such conditions, humans can be considered as a limited resource from the point of view of the cultural entities. On the short term, a cultural practice can spread quickly in spite of an important cost imposed to the individuals who display this practice, but it will sooner or later lead to the extinction of the population since no more individuals will be present in the surrounding of the "infected" individuals and the cost of the practice will not be compensated by a high level of transmission. On the contrary, a practice that, on average, allows for an increase in individuals' fitness will persist and will be transmitted over time since new individuals will always be available.

Once these considerations are taken into account, the relevance of multilevel selection and, more specifically, group selection of cultural items, becomes obvious. Ideas pass from one individual to the other within a cooperative group. Differences in religious practices between groups can lead to the differential persistence of these groups over time and potentially to their differential growth and "reproduction". Proselytism, wows of chastity, hostilities or intolerance towards other religious groups are all potential adaptive traits that are better explained from a long term cultural groups perspective, in spite of the short term individual cost. 
To conclude this section, I will briefly present three studies which have directly or indirectly tested theories of intergroup competition by considering some traits linked to religion as cultural adaptations. The first one has been made by Snarey (1996). Using an ethnographic database of several hundreds of variables and societies, he demonstrates that the beliefs in moralizing high gods (by "high" he means being an all-powerful and/or creator of the universe) is positively correlated with the dryness of the environment. Snarey suggests that the fact of believing in all powerful and moralizing god increases the cooperation between individuals in environments where the problem of water availability existed in the past or still has an important impact on the survival of the societies. Thus the result observed (i.e. the correlation between dryness and the presence of high gods in the religion) would be due to the elimination or transformation of the societies which did not have such beliefs in high gods.

The second study was carried by Roes and Raymond (2003), who used the same database and tested different hypotheses. They found that the beliefs in high gods were on average found more often in the largest societies (usually found in the richest environments). They propose that the beliefs in high gods allow societies to reach a larger size by promoting a better cooperation between individuals and consequently out-competing smaller groups since the size of a society is critical in intergroup competition involving conflicts. The mechanism they propose to explain the role of the beliefs in high gods and the size of societies is the following. A larger society faces problems such as free riding, defection of its individuals as well as the risk of splitting in a much more intense way than a smaller society where such problem can be solved at a local level. The belief in high moralizing gods would allow, according to Roes and Raymond, an increase in cooperation between individuals in a group, and thereby would lead to the partial solution of the free riding problem. This consequently would decrease the risk of scission of this group. Moralizing gods would serve, if we follow Roes and Raymond in their reasoning, as social glue.

Finally, a third study by Henrich and his collaborators (Henrich et al. 2010), has tested the impact of belonging to Islam and Christianity (what they name world religions) on the fairness of individuals in 15 populations. The study shows, among other results, that if the individuals tested belong to one of these two religions there is a higher probability that they will behave more fairly than when they belong to a local religion. Henrich and collaborators measured fairness using three games classically used by economists which involve the interaction of two individuals. In the first game, named "the dictator game", one of the two individuals receives a sum of money that he or she can choose to share with the other player. He or she can decide to keep everything or to divide this sum of money as he wishes. The second player has no choice but to accept the amount of money which is given to them. This is not the case in the second game, "the ultimatum game" where the second player can refuse the amount of money the first player intends to give them. If the second player refuses the amount proposed, none of them will receive the money initially given by the experimenter. Finally, Henrich and his collaborators created a game based on the same principles that the "dictator" and "ultimatum" games, but in which the second player can punish the first player by spending some money given 
to them beforehand if they believes that the proposition made by the first player is unfair. From the results they obtain, namely a higher probability to play the games fairly by individuals belonging to a world religion, Henrich and his collaborators suggest that world religions have coevolved with societies while facilitating large scale cooperation. The underlying idea behind this proposition is the concept of cultural group selection.

None of these three studies outlined above clearly proposes a specific mechanism involving religion that would reinforce individual cooperation within societies. For example, Roes and Raymond use the term "moralizing god" which remains very vague. The fear of supernatural punishment theory, the kleptocracy theory and some aspects of the costly signaling theory could potentially all be involved in some phenomena of moralization and of large scale cooperation observed by Snarey and Roes and Raymond on the one hand, and Henrich and his collaborators on the other hand.

None of the theories or hypotheses proposing religion as an adaptation at the group level is a theory that gives a historical and cognitive origin of religion. No cognitive mechanisms are proposed either in Snarey's study or in Roes and Raymond's one. Even Wilson, the great architect of the multilevel selection theory, neglects some explanations given by the other theories at the individual level which are sometimes simpler, more cognitively relevant and which do not involve the group level. Yet, as we saw, some questions linked to the diversity of religions, to some of their characteristics and to their stabilization over time will remain unanswered if they are considered from an individual level perspective only.

\section{Conclusion}

In this chapter I have proposed that different kinds of Darwinian theories could account for the origins and evolution of religious practices and beliefs. I have distinguished six theories (or sets of theories) and emphasized wherever possible that they are not incompatible since they are not always applicable to the same fields, the same levels of organization and over the same periods of the human evolution. For example, the by-product theory is a cognitive explanation of the origin of the beliefs in supernatural agents. The sweet-tooth theory might permit to provide cognitive explanations of the existence of deleterious religious behaviors from a modern individualistic perspective if more research was done within this framework. The fear of supernatural punishment provides a cognitive explanation of the origins of beliefs in supernatural moralizing agents. Kleptocracy and costly signaling theories respectively provide a pluralistic explanation of the emergence of the world religion and a behavioral explanation of the emergence of costly rituals. Finally, developing models of multilevel selection would certainly provide solid explanations of the evolution and maintenance of the number of the different religious traits and religions in the world. Table 36.1 summarizes all these differences between theories. It is now time to acknowledge that the integration will probably be the only way of providing the most thorough account on the evolution of Religion. Indeed, 
Table 36.1 Summary of the different theories of the emergence and evolution of religion

\begin{tabular}{l|l|l|l}
\hline Theory (proponents) & Explanatory power & $\begin{array}{l}\text { Level of } \\
\text { organisation } \\
\text { privileged }\end{array}$ & $\begin{array}{l}\text { Type of } \\
\text { explanation }\end{array}$ \\
\hline $\begin{array}{l}\text { By-product (Boyer, } \\
\text { Barrett) }\end{array}$ & $\begin{array}{l}\text { Emergence and stabilization } \\
\text { of beliefs in supernatural } \\
\text { agents }\end{array}$ & Individual & Cognitive \\
\hline Sweet-tooth (Dennett) & $\begin{array}{l}\text { Presence of behaviors } \\
\text { deleterious for the individual } \\
\text { in religions }\end{array}$ & Individual & Cognitive \\
\hline $\begin{array}{l}\text { Fear of supernatural } \\
\text { punishment (Johnson } \\
\text { and Bering) }\end{array}$ & $\begin{array}{l}\text { Beliefs in supernatural } \\
\text { agents concerned with and } \\
\text { enforcing human morality }\end{array}$ & individual & Cognitive \\
\hline $\begin{array}{l}\text { Kleptocracy (Diamond) } \\
\text { Emergence of "pyramidal" } \\
\text { religion or world religions in } \\
\text { agrarian societies. part of } \\
\text { their success in inter- } \\
\text { societies competition }\end{array}$ & $\begin{array}{l}\text { Individual (and } \\
\text { to some extent } \\
\text { beyond) }\end{array}$ & $\begin{array}{l}\text { Behaviorist with } \\
\text { pluralist } \\
\text { tendencies }\end{array}$ \\
\hline $\begin{array}{l}\text { Costly signaling (Sosis, } \\
\text { Cronk, Irons) }\end{array}$ & Emergence of costly rituals & Individual & Behaviorist \\
\hline $\begin{array}{l}\text { Multilevel with focus on } \\
\text { group level (Wilson; to } \\
\text { some extent, Roes and } \\
\begin{array}{l}\text { Raymond; Snarey; } \\
\text { Henrich et al.) }\end{array}\end{array}$ & $\begin{array}{l}\text { Emergence of some religious } \\
\text { characteristics such as } \\
\text { proselytism, stabilization and } \\
\text { modification of other } \\
\text { individual religious traits }\end{array}$ & $\begin{array}{l}\text { Individual and } \\
\text { beyond }\end{array}$ & $\begin{array}{l}\text { Rather } \\
\text { behaviorist but } \\
\text { ideally pluralist }\end{array}$ \\
\hline
\end{tabular}

we have seen that the fear of supernatural punishment theory to some extent rests on the by-product theory. We have also seen that the Kleptocracy theory could be linked both to the fear of supernatural punishment theory and consequently to the by-product theory but also to the costly signaling theory through the enforcement of rituals. Thirdly, the costly signaling theory could be linked to the fear of supernatural punishment which would provide at least a partial explanation of the reliability of some signals (such as being pious). Finally, it seems that the group level theories replaced in a multilevel framework are the best candidates to integrate those different theories, although one needs to keep in mind that the individual level and the cognitive constraints that it imposes need to be at the heart of a multilevel framework (what current group-level theories hardly do). I showed that some explanations, while resting on the individual level, only make sense when they are replaced in a more general context involving the existence of other cultural groups. A group of individuals is always hard to define, but it seems that if one chooses relevant cultural traits, as Sosis, Kress and Boster did in their study on scarifications, multilevel mechanisms integrated in the future models would provide a better general understanding of the origins and evolution of religion. The Fig. 36.1 schematically summarizes links which exist between the different theories we examined.

Figure 36.1 and Table 36.1 do not aspire to answer all the problems that would need to be solved in order to fully understand the emergence and evolution of reli- 
Fig. 36.1 Links between the different theories of the emergence and evolution of religion

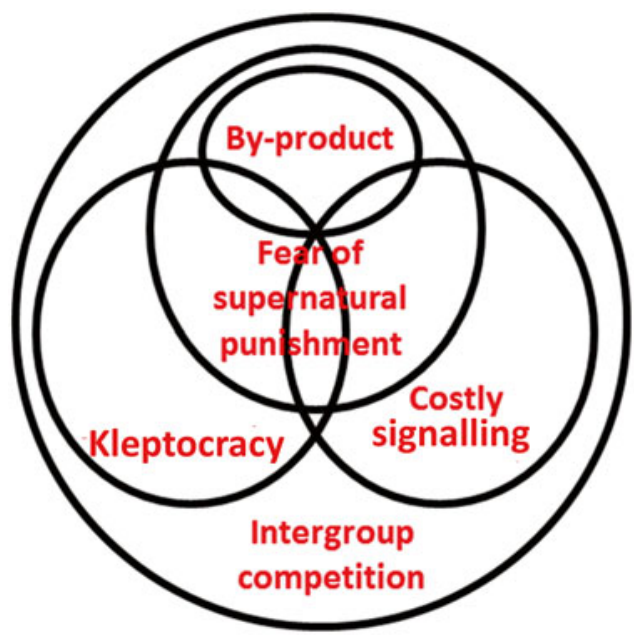

gion. However, I aimed at eliminating the direct oppositions and contradictions between these theories as well as to show their limits. Religion is an extremely complex phenomenon and the Darwinian approach to this phenomenon is still quite recent. It seems fair to give each theory involved in its explanation the time to develop and to find a consensus with other theories wherever possible.

The by-product theory of religion provides a very good non-adaptive cognitive explanation of the emergence of beliefs in supernatural agents. The fear of supernatural punishment theory, in the version proposed by Bering and Johnson, rests on the by-product theory but adds an adaptive dimension to the explanation of these beliefs. In order to account for their maintenance, a group-level dimension is necessary for this theory which has been build from an individual perspective. The same remark can be made both with regards to the kleptocracy and costly signaling theories. These two theories could be partially anchored to the fear of supernatural punishment theory and consequently into the by-product theory. The maintenance of the beliefs and practices entailed by those theories also implies a group-level perspective.

\section{References}

Alcorta, C. S., \& Sosis, R. (2005). Ritual, emotion, and sacred symbols the evolution of religion as an adaptive complex. Human Nature, 16(4), 323-359.

Alexander, R. (1987). The biology of moral systems. New York: Aldine de Gruyter.

Atkinson, Q. D., \& Bourrat, P. (2011). Beliefs about God, the afterlife and morality support the role of supernatural policing in human cooperation. Evolution and Human Behavior, 32(1), 41-49.

Atkinson, Q. D., \& Whitehouse, H. (2011). The cultural morphospace of ritual form: Examining modes of religiosity cross-culturally. Evolution and Human Behavior, 32(1), 50-62. 
Atran, S. (2002). In gods we trust: The evolutionary landscape of religion. Oxford: Oxford University Press.

Baron-Cohen, S. (1995). Mindblindness: An essay on autism and theory of mind. Cambridge, MA/ London: MIT Press.

Barrett, J. L. (2000). Exploring the natural foundations of religion. Trends in Cognitive Sciences, $4(1), 29-34$.

Barrett, J. L. (2004). Why would anyone believe in God? Walnut Creek: AltaMira Press.

Barrett, J. L., \& Keil, F. C. (1996). Conceptualizing a nonnatural entity: Anthropomorphism in God concepts. Cognitive Psychology, 31(3), 219-247.

Bering, J. M. (2002). The existential theory of mind. Review of General Psychology, 6(1), 3-24.

Bering, J. M., McLeod, K., \& Shackelford, T. K. (2005). Reasoning about dead agents reveals possible adaptive trends. Human Nature, 16(4), 360-381.

Betzig, L. L. (1986). Despotism and differential reproduction: A Darwinian view of history. New York: Aldine Publishing.

Bloom, P. (2004). Descartes' baby: How the science of child development explains what makes us human. New York: Basic Books.

Boster, J. S., Hudson, R. R., \& Gaulin, S. J. C. (1998). High paternity certainties of Jewish priests. American Anthropologist, 100(4), 967-971.

Bourrat, P., Atkinson, Q. D., \& Dunbar, R. I. M. (2011). Supernatural punishment and individual social compliance across cultures. Religion, Brain \& Behavior, 1(2), 119-134.

Boyer, P. (2001). Religion explained: The human instincts that fashion gods, spirits and ancestors. London: Basic Books.

Boyer, P., \& Ramble, C. (2001). Cognitive templates for religious concepts: Cross-cultural evidence for recall of counter-intuitive representations. Cognitive Science, 25(4), 535-564.

Buss, D. M., Haselton, M. G., Shackelford, T. K., Bleske, A. L., \& Wakefield, J. C. (1998). Adaptations, exaptations, and spandrels. American Psychologist, 53(5), 533-548.

Cronk, L. (1994). Evolutionary theories of morality and the manipulative use of signals. Zygon, 29(1), 81-101.

Dawkins, R. (1982). The extended phenotype: The long reach of the gene. New York: Oxford University Press.

Dawkins, R., \& Krebs, J. R. (1978). Animal signals: Information or manipulation? In J. R. Krebs \& N. B. Davies (Eds.), Behavioural ecology: An evolutionary approach (1st ed., pp. 282-309). Oxford: Blackwell.

Deacon, T. (1997). The symbolic species: The co-evolution of language and the brain. New York: W.W. Norton \& Co.

Dennett, D. C. (2006). Breaking the spell. New York: Vinking.

Diamond, J. (1987). The worst mistake in the history of the human race. Discover, 8(5), 64-66.

Diamond, J. (1997). Guns, germs and steel. New York: W.W. Norton \& Co.

Grafen, A. (1990). Biological signals as handicaps. Journal of Theoretical Biology, 144(4), 517-546.

Guthrie, S. E. (1993). Faces in the clouds: A new theory of religion. Oxford: Oxford University Press.

Henrich, J., Ensminger, J., McElreath, R., Barr, A., Barrett, C., Bolyanatz, A., et al. (2010). Markets, religion, community size, and the evolution of fairness and punishment. Science, 327(5972), 1480-1484.

Irons, W. (1996). In our own self image: The evolution of morality, deception, and religion. Skeptic, 4(2), 50-61.

Johnson, D. D. P. (2005). God's punishment and public goods: A test of the supernatural punishment hypothesis in 186 world cultures. Human Nature, 16(4), 410-446.

Johnson, D. D. P., \& Bering, J. (2009). Hand of God, mind of man. In J. Schloss \& M. J. Murray (Eds.), The believing primate: scientific, philosophical, and theological reflections on the origin of religion (p. 26). Oxford: Oxford University Press.

Johnson, D. D. P., \& Krüger, O. (2004). The good of wrath: Supernatural punishment. Political Theology, 5, 159-176. 
Krebs, J. R., \& Dawkins, R. (1984). Animal signals: Mind-reading and manipulation. In J. R. Krebs \& N. B. Davies (Eds.), Behavioural ecology: An evolutionary approach (2nd ed., pp. 380-402). Sunderland: Sinauer.

Laland, K. N., Odling-Smee, J., \& Feldman, M. W. (2000). Niche construction, biological evolution, and cultural change. Behavioral and Brain Sciences, 23(1), 131-146.

Maynard Smith, J., \& Szathmáry, E. (1995). The major transitions in evolution. Oxford: Freeman $\&$ Co.

Michod, R. (1999). Darwinian dynamics. Princeton: Princeton University Press.

Okasha, S. (2006). Evolution and the levels of selection. New York: Oxford University Press.

Pinker, S. (1997). How the mind works. New York: Norton.

Premack, D., \& Woodruff, G. (1978). Does the chimpanzee have a theory of mind? Behavioral and Brain Sciences, 1(4), 515-526.

Richerson, P. J., \& Boyd, R. (2005). Not by genes alone: How culture transformed human evolution. Chicago: University of Chicago Press.

Roes, F. L., \& Raymond, M. (2003). Belief in moralizing gods. Evolution and Human Behavior, 24(2), 126-135.

Snarey, J. (1996). The natural environment's impact upon religious ethics: A cross-cultural study. Journal for the Scientific Study of Religion, 35(2), 85-96.

Sosis, R. (2000). Religion and intragroup cooperation: Preliminary results of a comparative analysis of Utopian communities. Cross-Cultural Research, 34(1), 70-87.

Sosis, R., \& Alcorta, C. (2003). Signaling, solidarity, and the sacred: The evolution of religious behavior. Evolutionary Anthropology, 12(6), 264-274.

Sosis, R., \& Bressler, E. R. (2003). Cooperation and commune longevity: A test of the costly signaling theory of religion. Cross-Cultural Research, 37(2), 211-239.

Sosis, R., Kress, H. C., \& Boster, J. S. (2007). Scars for war: Evaluating alternative signaling explanations for cross-cultural variance in ritual costs. Evolution and Human Behavior, 28(4), 234-247.

Tremlin, T. (2006). Minds and gods: The cognitive foundations of religion. New York/Oxford: Oxford University Press.

Van Valen, L. (1973). A new evolutionary law. Evolutionary Theory, 1(1), 1-30.

Whitehouse, H. (2004). Modes of religiosity: A cognitive theory of religious transmission. Walnut Creek/Oxford: Altamira Press.

Wilson, D. S. (2002). Darwin's cathedral: Evolution, religion, and the nature of society. Chicago: University of Chicago Press.

Wilson, D. S. (2005). Testing major evolutionary hypotheses about religion with a random sample. Human Nature, 16(4), 382-409.

Wilson, D. S., \& Wilson, E. O. (2007). Rethinking the theoretical foundation of sociobiology. The Quarterly Review of Biology, 82(4), 327-348.

Wiltermuth, S. S., \& Heath, C. (2009). Synchrony and cooperation. Psychological Science, 20(1), $1-5$.

Zahavi, A. (1975). Mate selection-a selection for a handicap. Journal of Theoretical Biology, 53(1), 205-214.

Pierrick Bourrat I work mainly on the conceptualization of natural selection and issues related to fitness, drift and levels of selection. My background is in evolutionary biology, cognitive sciences and philosophy of sciences. 